\section{ST. GEORGE'S HOSPITAL.}

8EVTRANCE OF THE LEG FROM THE THIGH: TENSIVE INJURY TO THE GREAT SCIATIC NERVE: PRACTURE OF THE FEMUR: FRACTURE OF THE PBLTIS, AND IACERATION OF THE BLADDEB: PRIMARY AMPUTATION : DEATH.

Under the care of Gronge D. Pownock, Esq., Assistant.Surgeon to the Hospital.

$\triangle$ Bor, aged 8, was admitted on the afternoon of Oct. 31, in consequence of an accident, in which the left leg had been severed from the body. He had, it seemed, been riding behind a cab, and had somehow slipped, with his leg between the spokes of the wheel. When brought into the hospital, it was found that the end of the femur, covered only by its articular cartilage, was projecting out of the soft parts. The skin was cleanly torn, all round, a very little way above the flexure of the joint. The popliteal vessels were of course exposed in the wound, but did not bleed. Notwithstanding the little hrmorrhage, he was in a state of great depression, and had suffered some severe injury about the pelvis. As this injury, however, did not affect the treatment of the case, and as examination in that part gave great pain, it was not further investigated. On examining the severed leg, it was found that the capsular and crucial ligaments of the knee had been torn close to their insertion into the femur, and the extensor tendon torn away from the patella, leaving that bone attached to the tibia. The most extraordinary feature in the injury, however, was that the whole length (as it appeared) of the sciatic nerve remained attached to the leg. The length of nerve above the knee-joint was $19 \frac{1}{2}$ inches, while the length of the leg was 10 inches only; and the cord terminated above in two smaller branches, which were judged to be parts of the acral plexus itself; as, indeed, they proved to be on dissection. The femur was fractured at the junction of its upper and middle third.

It was soon seen that the bladider was lacerated, by his inability to pass water, by the absence of injury to the urethra, and by the small quantity of urine, loaded with blood, which was drawn off by the catheter. Still, it was impossible to leave the stump in the condition above described; and accordingly, when he had sufficiently recovered from the collapse, Mr. Pollock remored the limb by the flap amputation, through the fracture. It was thought imprudent, in his very weak condition, to give chloroform and the operation was accordingly performed without. It was noticed, while the flaps were being stitched together, that the posterior flap appeared insensible. On examining the thigh, a portion of the nerve (supposed to be that corresponding to the external popliteal branch) was found in the usual situation. The end of the artery was shrunk, and it contained a small clot of blood.

Little need be said as to the progress of so hopeless a case. Symptoms of peritonitis soon camc on ; and a catheter, which had been tied in the bladder, caused so much pain that it was necessary to remove it. His extreme weakness contraindicated the use of the measures usual in peritonitis, and it was necessary to trust merely to his constitutional strength to carry him through the complication of injuries under which he laboured. He struggled on for two days, and then died of exhaustion.

On post mortem examination it was found that the sciatic nerve had sprung from the sacral plexus in two parts, and that of these parts one, which arose from the upper cords of the plexus, was entire, while the other was broken off at the exit of the lower two sacral nerves from the sheath of the spinal cord. There was a little blood extravasatcd in the neighbourhood of the laceration, but all the parts within the thece vertebralis were quite healthy. The pelvis was extensively injured, lines of fracture passing through both sacro-iliac joints and through the ramus of the right os pubis, about an inch from the symphysis. The outer fragment of the last-nnmed fracture had perforated the floor of the bladder at that part, and bruised its opposite wall ; urine was extravasated into the cellular tissue of the pelvis. The peritoneal cavity showed traces of recent inflammation.

RexnRKs. The preceding case is interesting, less on account of any surgical instruction that can be deduced from it, than the rarity of the anatomical lesions which it presented. The force acting must have been enormous, since it serered all the ligaments of the knee, and tore through the integuments orer that joint, thus completely separating the leg from the thigh: yet the sciatic nerve alone of all the structures around the joint resisted or escaped this tremendous violence, and was only severed at its origin from the sacral plexus, I suppose, by the separated limb being dragged away from the body: for the force which acted so abruptly at the knee-joint as to snap the limb into two pieces at that part, could hardly be supposed to have transmitted its action to the inside of the pelvis, nor was there anything to show that the laceration of the nerve had been produced by the fracture of the pelvic bones. The vessels, although they usually resist such injuries more successfully than nerves, had given way at the same level as the less elastic ligaments; the contusion, however, of their extremities kept their mouths closed and prevented hæmorrhage. The case was one in which an operation was necessary, howerer feeble the chance of recovery, as the whole end of the femur was entirely denuded of soft parts, nor did the amputation (which was, it will be observed, performed through a part of the bone fractured by the accident) appear to add to the great depression previously existing. The laceration of the bladder coexisting with such extensive injury, of course rendered the case hopeless, but is not by itself a necessarily fatal injury when it occurs external to the peritoneal cavity. Chelius (in South's translation) goes to the length of saying that it is "not rery dangerous". He must, however, be understood, I suppose, to mean in cases of compound fracture where the urine has an exit, or where it has shown itself in the perinæum and an exit has been given it by incision. In the other case (as in the instance before us), where it makes its way backwards into the subperitoneal cellular tissue, thus exciting inflammation on the other side of the serous. membrane also, I do not see that its dangers are much less than those attending laceration into the peritoneal cavity itself.

\section{LIVERPOOL NORTHERN DISPENSARY.}

\section{HXNORRHAGE AFTER OPERATION WITH THE ECRASEU R.}

By L. E. Desyond, B.A., Honorary Surgeon to the Dispensary, and late Surgeon to the Lying-in Hospital.

Ir has generally been supposed that the great advantage of operating with the écraseur, in removing hæmorrhoidal and other tumours, is the avoidance of hamorrhage, while the patient is spared the pain of the ligature; and, from all that has been said and written on the subject, the surgeon may possibly accept this as universally true, and thus be thrown off his guard as to the necessity of watching those cases in which he has operated for the removal of internal piles, or of redundant mucous membrane. It is with a view of cautioning the profession against this supposed security, that the following unfortunate case is recorded; for doubtless as much valuable information and experience is to be derived from the knowledge of our failures, as from our successes. 